\title{
Crisis management practices in the hospitality and gambling industry during COVID-19
}

Kasra Ghaharian

International Gaming Institute and William F. Harrah College of Hospitality, University of Nevada, Las Vegas, Nevada, USA

Brett Abarbanel

International Gaming Institute, University of Nevada, Las Vegas, Nevada, USA and Gambling Treatment and Research Clinic, University of Sydney, Sydney, Australia Marta Soligo

International Gaming Institute and Department of Sociology, University of Nevada, Las Vegas, Nevada, USA, and

Bo Bernhard

International Gaming Institute and William F. Harrah College of Hospitality, University of Nevada, Las Vegas, Nevada, USA

\begin{abstract}
Purpose - The purpose of this paper is to examine crisis management practices among gambling-related hospitality business stakeholders (GBSs) during the coronavirus disease 2019 (COVID-19) pandemic.

Design/methodology/approach - An online survey was administered to a sample of GBSs resulting in 64 completed surveys. The survey explored the COVID-19 crisis using a three-phase framework: preparedness (prior experience and response plans), response (level of importance and use of crisis practices) and future (confidence in recovery, beliefs about consumer behavior and new strategies). Independent-samples $t$-tests were conducted to investigate the influence of preparedness variables on crisis management capabilities. Importance-Performance Analysis was used to evaluate GBSs' crisis management capabilities and identify where performance might be improved. Factor analyses were employed to explore groupings of response practices as well as future strategies.

Findings - Prior experience had a significant impact on GBSs' crisis management. IPA indicated gaps between the importance GBSs assign to response practices and their corresponding level of use, specifically for those related to marketing and government. Factor analysis revealed response practices did not group according to the questionnaire's four themes, instead, three themes of marketing, efficiency and expenses were revealed. Prevention and hygiene emerged as dominant themes with respect to future strategies.

Originality/value - This is a timely study that investigates crisis management among GBSs during the COVID-19 pandemic. It provides important methodological contributions as well as valuable practical considerations for gambling-related hospitality businesses.
\end{abstract}

Keywords Crisis, Importance-performance analysis, COVID-19, Gambling, Hospitality, Resorts

Paper type Research paper

\footnotetext{
(C) Kasra Ghaharian, Brett Abarbanel, Marta Soligo and Bo Bernhard. Published in International Hospitality Review. Published by Emerald Publishing Limited. This article is published under the Creative Commons Attribution (CC BY 4.0) licence. Anyone may reproduce, distribute, translate and create derivative works of this article (for both commercial and non-commercial purposes), subject to full attribution to the original publication and authors. The full terms of this licence may be seen at http:// creativecommons.org/licences/by/4.0/legalcode

Disclosure statements: The authors have no conflicts of interest to declare for the publication of this work.
} w.

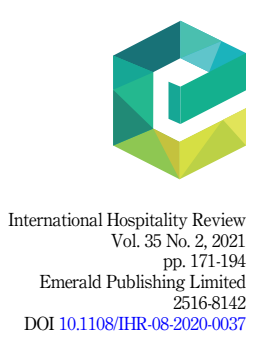


IHR

35,2

\section{Introduction}

The coronavirus disease 2019 (COVID-19) pandemic is challenging industries around the world. Preventative measures to combat the spread of the virus, such as mandated business closures, physical distancing, reduced community mobility and travel restrictions, have been especially devastating to the hospitality industry (Gössling et al., 2020). Perhaps one of the more vulnerable subsectors has been gambling-related hospitality businesses, such as casino resorts. These businesses often rely on tourism and international air travel and many of resorts' verticals, such as casinos, are synonymous with gatherings of large groups of people in close proximity (Shivdas, 2020). Unfortunately, these features, within which this industry thrives, also abet the spread of the virus (Centers for Disease Control and Prevention, 2020a, b).

The disruption to the gambling industry is clear. In Macau, famed for its numerous casino resorts and the world's largest gambling market, authorities in February 2020 ordered casinos to close for a 15-day period to curb the spread of the virus (Shriber, 2020) and gross gaming revenue (GGR) for that period dropped 87.8\% YoY (Gaming Inspection and Coordination Bureau, 2020). But travel restrictions and quarantine orders in Macau's key feeder markets, such as mainland China, have had more lasting effects (Hong and Wei, 2020). Revenues reached an all-time low in June 2020 and the region reported a $77.4 \%$ decline in June year-to-date GGR (Gaming Inspection and Coordination Bureau, 2020). A similar scenario is apparent elsewhere around the world, including Australia, parts of Europe, and the United States, where casinos and other hospitality operations began closing their doors in March 2020 (Cherney, 2020). Establishments in some jurisdictions began to open midway through the year, but as with Macau, signs of recovery are unpromising. In Las Vegas, for example, casino resorts reopened for customers on June 4,2020, albeit with hefty preventative practices in place, including enhanced hygiene, limited seating capacity, personal protective equipment, and increased use of technology-based services (Okada, 2020). Despite this reopening, the Las Vegas economy still suffered. For June 2020, air passenger traffic at the city's McCarran International Airport was down 77\% year-over-year (Las Vegas Convention and Visitors Authority, 2020a), and the city greeted just 1,065,100 visitors, representing a 71\% decline from the 3,607,400 during the same month a year prior (Las Vegas Convention and Visitors Authority, 2020b). Furthermore, the Nevada Gaming Control Board (NGCB) reported massive declines in year-over-year GGR in June 2020 for the Las Vegas Strip and state-wide; $-61.36 \%$ and $-45.55 \%$, respectively (NGCB, 2020). The path to recovery remains uncertain for these casino resort businesses as operators wrestle with the impending crisis.

Uncertainty itself is not new; hospitality and gambling industries have faced crises in the past and crisis events in these industries have been described as inevitable (Barton, 1994). Natural disasters, for example, have had short-term direct impacts to specific locales. In August 2019 casinos in Atlantic City, NJ were forced to close for three days when Category 1 Hurricane Irene stormed the city (Harper, 2019). Economic crises, meanwhile, have had farther reaching impacts. As a result of the 2008 financial crisis, commercial casino sector revenues in the United States dropped 4.7\% year-over-year (Horváth and Paap, 2012), and a 2012 study conducted during the Spanish financial crisis revealed decreases in the frequency of gambling activities, the number of gambling activities partaken in, and the amount of money wagered (Science Daily, 2020). Notably, prior viral outbreaks have had significant effects. The damage to the Mexican tourism industry as a result of the $2009 \mathrm{H} 1 \mathrm{N1}$ pandemic was valued at US $\$ 5 \mathrm{bn}$ and the 2003 severe acute respiratory syndrome (SARS) outbreak was calculated to negatively affect the entire global travel and tourism sector by an estimated US\$30-50bn (World Travel and Tourism Council, 2020). Despite these occurrences and the industries' inherent higher sensitivity to crises (Kim et al., 2005), research in the area of crisis preparedness and management for hospitality and gambling spaces is still in its infancy (Israeli et al., 2018). Furthermore, while a limited number of crisis management studies have focused on destinations, hotels, and airlines as units of analysis, the authors did not uncover 
any prior work purposefully exploring gambling-related hospitality businesses and this research begins to fill this gap in the academic literature.

Recommendations and identification of key strategies are desperately needed for gambling industry management to better navigate the uncertain path ahead. Moreover, the hospitality and gambling industries are important vehicles for COVID-19 crisis research. As part of the wider service sector, they make substantial contributions to Western economies, making the minimization of impacts and timely recovery imperative (Smith, 2005). Accordingly, the purpose of this study is to expand knowledge about crisis management in gambling-related hospitality businesses during the COVID-19 pandemic. More specifically, the aims are threefold: (1) to evaluate crisis management practices of gambling-related hospitality business stakeholders (GBSs) in response to the pandemic, (2) to assess how their preparedness relates to their response, and (3) to explore their beliefs and expectations as the pandemic recedes in the future.

\section{Literature review}

\subsection{Crisis management models}

The shock of the COVID-19 pandemic and disruption to regular business function has demanded action from leadership to mitigate the effects. The activities and practices pertaining to this unprecedented situation are encompassed by the term crisis management. As Kim et al. (2005) point out, these “. . .activities pertain not only to the hectic moments of crisis decision-making but also to the managerial areas of long-range prevention, preparation and mitigation, the response immediately following the crisis and the sensitive domain of recovery and change" (p. 371).

Various models have been proposed to explain the phenomenon and help guide management through crises (see, e.g. Caplan, 1970; Arnold, 1980; Slatter, 1984; Smith, 1990; Booth, 1993; Smith and Sipika, 1993; Seymour and Moore, 2000; and Faulkner, 2001). These models often depict crisis management as a sequence or cycle, with a number of events or phases. For example, Faulkner's (2001) Tourism Disaster Management Framework segments crisis management into no more than six sequential phases. The framework begins with the pre-event phase, in which contingency plans are developed. The prodromal phase follows, in which previously developed plans are initiated. The emergency and intermediate phases characterize actions and practices during the crisis. The recovery phase is associated with longterm actions postcrisis, and the resolution phase sees management evaluate prior actions. In reality, however, the phases may not be mutually exclusive and likely unfold in a more random sequence (Faulkner, 2001). As with COVID-19, crises are often unexpected, offering leadership little opportunity for formal planning and preparation (Pforr and Hosie, 2008). Indeed, the "reopening" of the US economy (after the initial COVID-19 surge in early 2020) has been less than linear. Different states relaxed preventative restrictions at different timepoints, and with virus trends varying across the nation some have reversed course (The Washington Post, 2020). For example, in California restaurants closed on March 15th for in-person dining, then began to open again in late May only to close again in July (Snyder and Harris, 2020).

A more appropriate framework to assess the management of the COVID-19 crisis may be a more simplistic one. Periods of crises could be categorized into three straightforward stages: before, during, and after. This is in accordance with Heath's (1998) general aims of crisis management for managers and executives, which are (1) to plan and provide for possible crisis events (the pre-crisis stage), (2) to reduce or mitigate the impacts of a crisis by improving the response management (the crisis stage), and (3) to swiftly and effectively determine the damage caused by the crisis (the post-crisis stage). Similarly, Smith and Sipika (1993) conceptualize three aspects of crisis management with a feedback loop to indicate the role of organizational learning in recovery and a return to the status quo; (1) crisis of management (pre-crisis period), (2) operational crisis (crisis period), and (3) crisis of legitimation (post-crisis 
IHR

35,2

period). Additionally, 4-stage crisis management models are commonly utilized by organizations and can easily be applied to hospitality businesses; mitigation, preparation, response, recovery (MPRR) and prevention, preparation, response, recovery (PPRR) (Pforr and Hosie, 2008). These models represent a cycle of events that encourage learning. Yet, as noted prior, crises often do not occur in a linear fashion and the preparation, response and recovery are interconnected (Pforr and Hosie, 2008). Accordingly, this study explores the COVID-19 crisis using a three-phase framework: preparedness, response and future.

\subsection{Evaluating crisis management practices}

Prior literature has investigated the response of particular industries or sectors to specific crisis events; for example, terror events (e.g. 9/11), biological events (e.g. SARS), and airline crash accidents. While there is no prior academic literature explicitly studying crisis management practices in gambling-related hospitality businesses, the related tourism applications of hotels (Israeli and Reichel, 2003; Henderson and Ng, 2004; Kim et al., 2005; Tse et al., 2006; Israeli et al., 2011, 2018), restaurants (Green et al., 2004; Israeli, 2007a), travel agencies (Lovelock, 2004; Perl and Israeli, 2011), and airlines (Aderighi and Cento, 2004; Chang et al., 2018; Varma, 2020) are common case studies. Although gambling-related operations are easily distinguished from their hospitality industry counterparts (via the availability of gaming activities), the similarities are more pronounced. The non-gaming amenities, such as hotel accommodations, restaurants, entertainment, and nightlife, provided by gambling-related businesses often encompass the entire spectrum of hospitality offerings (Min et al., 2019), making the aforementioned literature fitting frameworks for this study. Meanwhile, a variety of methodologies have been employed to explore crisis management practices, but there is no consensus on a universal approach (Chang et al., 2018).

The Importance-Performance Analysis (IPA) method, used as a theoretical framework for this research, has been broadly applied to numerous different sectors and crises (Israeli and Reichel, 2003; Israeli, 2007a; Israeli et al., 2011, 2018; Perl and Israeli, 2011; Lai and Hitchcock, 2015; Chang et al., 2018). Initially developed to formulate customer service marketing practices (Martilla and James, 1997), IPA assigns predetermined attributes (defined in this study as practices) into four quadrants of a two-dimensional matrix based on their level of importance and level of performance (defined in this study as usage). The quadrants are categorized as (1) "concentrate here" (high importance and low use), (2) "keep up the good work" (high importance and high use), (3) "low priority" (low importance and low use), and (4) "possible overkill" (high importance and low use). Effective management is characterized by a matching of practice importance and performance (Duke and Persia, 1996; Israeli, 2007b). In the context of this study, IPA allows for the evaluation of crisis management practices that GBSs deem important and which practices they actually utilize amid a crisis situation (defined in this study as the response phase). The IPA approach begins with the selection of attributes; in this study, attributes are defined as crisis management practices.

Israeli and Reichel (2003) constructed a comprehensive list of crisis management practices to evaluate hotel managerial response to the Israeli hospitality industry crisis (2000-2002) that stemmed from escalating terrorist activity. Twenty-one practices were identified, from which four main themes emerged: human resources, marketing, maintenance, and government. The practices were used to build the Hospitality Crisis Management Questionnaire (HCMQ); a two part questionnaire in which respondents first rate the level of importance of each practice on a 7-point Likert scale $(1=$ least important, $7=$ most important) and then rate their level of use of each practice on a similar scale $(1=$ rarely used, $7=$ extensively used). Since this seminal study, the HCMQ has been adapted to assess managerial response to different crises in a variety of industries around 
the world, such as the Israeli restaurant industry (Israeli 2007a), Indian luxury hotels (Israeli et al., 2011), the Israeli travel agency sector (Perl and Israeli, 2011), and Turkish hotel managers (Israeli et al., 2018).

\subsection{Research questions and hypotheses}

The study's first two research questions concern the response phase and replicate propositions made in prior studies employing the HCMQ (Israeli and Reichel, 2003; Israeli, 2007a; Israeli et al., 2011, 2018; Perl and Israeli, 2011):

(1) Research question 1 (RQ1): For GBSs, is there a relationship between the reported importance of specific crisis management practices and their level of use?

RQ1 examines if GBSs engage in crisis management practices that they believe to be important; a necessary condition for effective crisis management (Duke and Persia, 1996; Israeli, 2007b). Based on prior literature, this study proposes the following hypothesis:

H1. There will be a significant positive association between the reported importance of specific crisis management practices and their level of use.

(2) Research question 2 (RQ2): Do GBSs' practices in response to COVID-19 conform to established themes in crisis management literature?

RQ2 examines whether GBSs' practices (for both level of importance and use) during the COVID-19 pandemic conform to the original HCMQ's constructs or do they reveal alternative patterns pertinent to the industry and current crisis. Based on prior literature, this study proposes the following hypothesis:

H2. Both importance and use will follow the four constructs of the HCMQ: human resources, marketing, maintenance, and government.

RQ3 and RQ4 investigate the preparedness phase and will assess the relationship between readiness and the crisis management response of GBSs:

(3) Research question 3 (RQ3): Is the existence of a formal crisis response plan related to GBSs' ability to utilize practices they believe to be important?

(4) Research question 4 (RQ4): Is prior crisis management experience related to GBSs' ability to utilize practices they believe to be important?

RQ3 and RQ4 explore the future phase and GBSs' confidence in recovery and expected changes in consumer behavior:

(5) Research question 5 (RQ5): How confident are GBSs in the recovery of their operation from the COVID-19 pandemic?

(6) Research question 6 (RQ6): To what extent do GBSs believe customers will reduce their spending toward travel and leisure activities?

RQ7 aims to identify which future strategies group together and whether any consistent themes are revealed that provide insight into future management practices with respect to the COVID-19 pandemic.

(7) Research question 7 (RQ7): How do GBSs' attitudes toward future strategies to combat the COVID-19 pandemic group together?

Extant literature does not establish a priori knowledge to suggest predicted relationships for RQ3 - RQ7, so hypotheses are not advanced for these questions. 
IHR

35,2

\section{Methodology}

This study was preregistered online with the Center for Open Science prior to the collection of any data. All analyses in the preregistered data analysis plan are presented in the Results section, regardless of statistical significance of findings, in line with Open Science best practices (Center for Open Science, 2020). Preregistration documentation can be found at https://osf.io/hej3y.

\subsection{Data collection and participants}

An online survey was developed to assess GBSs' experiences during the COVID-19 pandemic. An email invitation with link to the Qualtrics-hosted survey was sent to a list of approximately 200 faculty members and alumni of the Executive Development Program (EDP), who participated in the program between 2013 and 2019. EDP is a 10-day development program hosted annually by the University of Nevada, Las Vegas International Gaming Institute and the University of Nevada, Reno College of Business and Extended Studies, as an executive educational program for executives, owners, senior managers, and other leaders in gambling-related hospitality businesses. EDP alumni work in jurisdictions around the world and continue to participate in the EDP program via informal networking events throughout the year. The survey was distributed during the first week of May 2020, with a follow-up email invitation sent approximately one week after the initial invitation. Respondents were not reimbursed for their participation. Ethics approval for this study was received from the [University of Nevada, Las Vegas] Institutional Review Board.

\subsection{Measurement}

Variables are summarized here, and readers can refer to the full survey (https://osf.io/phkdn/) and in the associated preregistration project folder on OSF.io. The online survey composed of four parts. The first portion pertained to general demographic data and information about the respondent and their organization. The subsequent sections pertained to three phases of the COVID-19 crisis; preparedness, response, and future.

3.2.1 Preparedness. Drawing from Pforr and Hosie's (2008) indicators of preparedness, participants were asked two dichotomous questions, (1) "Does your operation have a formal crisis response plan?" and (2) "Has your operation experienced a crisis before?". Follow-up questions inquired about the respondents' role in their organization's crisis response plan and the nature of the past-experienced crisis/crises (e.g. natural disaster, economic crisis, biological crisis, etc.).

3.2.2 Response. An adapted version of the HCMQ was used to evaluate GBSs' crisis management practices; their response. Given the global representation of the sample population, practice 21 from the original questionnaire, "industry-wide demand for a grace period on local tax payments", was omitted. Additionally, the research team modified the wording of some practices with more specific gambling-industry jargon and terms. For example, "marketing to domestic tourists" was modified to "marketing to locals", and the word "hotel" was deleted from "cost cuts by limiting hotel services". The subsequent tool comprises 20 practices and two parts. Respondents first rated the importance of each practice on a 7-point Likert scale where $1=$ least important and $7=$ most important. Respondents then specified their level of actual use of each practice on a similar 7-point Likert scale where $1=$ rarely used and $7=$ extensively used. Table 1 lists the practices and corresponding themes.

3.2.3 Future. Three questions were used to explore GBSs' beliefs about the future of their organization and the industry more broadly. The first question gauged respondents' confidence in their operation's recovery from COVID-19 on a 5-point Likert scale, where $1=$ Extremely doubtful and $5=$ Extremely confident. To investigate beliefs about changes 


\begin{tabular}{|c|c|c|c|}
\hline Theme & Practice & Description & \\
\hline \multirow{6}{*}{$\begin{array}{l}\text { Human } \\
\text { resources }\end{array}$} & HR1 & Laying off employees to reduce labor force & practices during \\
\hline & HR2 & Using unpaid vacation to reduce labor force & \\
\hline & HR3 & Reducing the number of workdays per week & \\
\hline & HR4 & Freezing pay rates & \\
\hline & HR5 & Replacing highly paid employees with new low paid employees & \\
\hline & HR6 & Increased reliance on outsourcing & 177 \\
\hline \multirow[t]{7}{*}{ Marketing } & MK7 & Marketing to locals in joint campaigns with local merchants & \\
\hline & MK8 & Marketing to locals with focus on specific attributes of the location & \\
\hline & MK9 & Price drop on special offers & \\
\hline & MK10 & Reduce prices & \\
\hline & MK11 & $\begin{array}{l}\text { Marketing to nonlocals with specific focus on the location's distinctive features } \\
\text { and relative safety }\end{array}$ & \\
\hline & MK12 & Marketing and promoting new products or services & \\
\hline & MK13 & Marketing to new segments & \\
\hline \multirow[t]{4}{*}{ Maintenance } & MA14 & Cost cuts by limiting services & \\
\hline & MA15 & Cost cuts by postponing maintenance of the building (cosmetics) & \\
\hline & MA16 & Cost cuts by postponing maintenance to the engineering systems & \\
\hline & MA17 & Extending credit or postponing scheduled payments & \\
\hline \multirow[t]{3}{*}{ Government } & GV18 & Organized protest against the lack of government support & \\
\hline & GV19 & Industry-wide demand for governmental assistance with current expenses & Crisis management \\
\hline & GV20 & Industry-wide demand for a grace period on tax payments & \\
\hline
\end{tabular}

in consumer behavior, respondents used a 5-point scale $(1=$ not at all, $5=$ a great deal $)$ to indicate the extent to which they thought customers would reduce their spending toward different hospitality activities (e.g. gambling, live entertainment). Finally, respondents were asked to rate how likely they were to implement strategies with respect to the future of their operation, using a 5-point Likert scale for which $1=$ Extremely unlikely and $5=$ Extremely likely. This list of potential strategies was compiled using the Occupational Health and Safety Administration's (OSHA) workplace preparation guidelines for COVID-19 (OSHA, 2020), and supplemented by major topics identified by participants at "EDP reconvenes"; virtual meetings that were held throughout April 2020 that provided EDP faculty and members a platform to share their experiences and knowledge pertaining to the pandemic.

\subsection{Data analysis}

Statistical analysis was conducted using SPSS 26. Missing data were excluded on a list-wise basis. To empirically test whether GBSs practiced effective crisis management (RQ1), Spearman correlation tests were applied to all HCMQ responses to determine the association between the level of importance and level of use assigned to each practice (Israeli and Reichel, 2003). H1 will be affirmed if a strong positive correlation between each practices' importance and level of use is detected. Spearman correlations were used as they are nonparametric; HCMQ items are measured on ordinal scales and may be non-normally distributed (Kendall, 1938; Spearman, 1904). While the correlation analysis indicates whether management is acting effectively at a basic level, it does not provide deeper insight with respect to individual practice discrepancies between beliefs and actions. Therefore, the original protocol developed by Israeli and Reichel (2003) was supplemented with gap analysis. With IPA, a performance gap exists when there is a significant difference between an attribute's importance and performance ratings (O'Neill and Palmer, 2004). In this study, the gap is defined as importance minus use. Individual paired sample $t$ tests were conducted on the means of each practices' importance and use, to detect whether differences were meaningful. A positive gap (lower use than importance) indicates potential areas for improvement and the magnitude of the gap can 
IHR

35,2

assist management in prioritizing improvement efforts. However, results can elicit the same or similar sized gap for multiple practices, leading to a conundrum. To resolve this, an importance-weighted gap method was applied to help prioritize practices that show similar performance gaps (Chang et al., 2018). The priority value of a practice was calculated by multiplying the gap of a practice by the corresponding mean of the level of importance. Practices with statistically significant gaps were listed from highest to lowest according to their corresponding priority value to facilitate comparison.

To empirically test whether GBSs' practices in response to COVID-19 conform to the constructs of the HCMQ (RQ2) this study employed the analysis protocol utilized by prior work (Israeli and Reichel, 2003; Israeli, 2007; Israeli et al., 2011, 2018; Perl and Israeli, 2011). A principal component analysis (PCA) with a varimax rotation method with Kaiser normalization was deployed to determine which practices cluster and correspond to the four original constructs; human resources, marketing, maintenance, and government. A loading cut-off value of 0.45 was used for item inclusion (Tabachnick and Fidell, 2013). The PCA was applied to three categories of scale measures: (1) Response-level of importance measures, (2) Response-level of use measures, and (3) Response-effectiveness (calculated as the product of the importance and use of each practice). $\mathrm{H} 2$ is affirmed if the practices group according to the original constructs.

To assess whether GBSs who indicate better readiness display more effective crisis management (RQ3 and RQ4), 2 two-sample $t$-tests with checks for equality of variance were performed. For the first test, the independent variable was called CRISP, binary coded as $1=\mathrm{a}$ formal plan was in place prior to the COVID-19 pandemic, and $0=$ no formal plan existed. The second test examined a variable called CRISE, binary coded as $1=$ the respondent's operation had experienced a crisis before, and $0=$ the operation had not experienced a crisis before. The dependent variable for both tests was effectiveness (the product of importance and use). Cohen's $d$ was used to assess the effect size for mean comparisons.

Frequency counts and percentages were calculated for responses to questions regarding confidence in recovery (RQ5) and beliefs with respect to changes in consumer spending on hospitality activities (RQ6). Means were calculated for responses to the question "Reflecting upon the COVID-19 pandemic, please rate how likely you are to implement the following strategies with respect to the future of your operation". An exploratory factor analysis (EFA) was performed to identify the main themes with respect to respondents' likelihood to implement future strategies to combat the crisis (RQ7). Oblimin (oblique) rotation was used to permit for potential correlation between factors, as this analysis was exploratory. A loading cut-off value of 0.45 was used for item inclusion (Tabachnick and Fidell, 2013), with both eigenvalue criterion and scree test used to identify the number of dimensions.

For all factor analyses, Kaiser-Meyer-Olkin measure of sampling adequacy was calculated to determine if the analysis was appropriate for the data set, with a minimum acceptance level set at 0.50 (Field, 2013). Bartlett's test of sphericity was reviewed, with rejection criterion set at 0.05 . The reliabilities of dimensions were assessed using Cronbach's alpha ( $\alpha \geq 0.65$; Vaske, 2008).

\section{Results}

83 responses were collected, comprising a response rate of roughly $40 \%$. Of these, 64 responses were useable for analysis. However, six responses for the HCMQ items were incomplete and removed from the sample for that portion of the analysis. The relevant sample size for each analytical step is indicated in table footnotes. Descriptive statistics, including the mean, median, SD, and range were calculated for all variables. Table 2 presents the sample descriptive statistics. 


\begin{tabular}{|c|c|c|c|}
\hline Variables & $N$ & $\%$ & Crisis \\
\hline $\begin{array}{l}\text { Gender } \\
\text { Male } \\
\text { Female } \\
\text { Self-identify }\end{array}$ & $\begin{array}{r}50 \\
13 \\
1\end{array}$ & $\begin{array}{r}78.1 \\
20.3 \\
1.6\end{array}$ & $\begin{array}{r}\text { practices during } \\
\text { COVID-19 }\end{array}$ \\
\hline $\begin{array}{l}\text { Age } \\
20-29 \text { years } \\
30-39 \text { years } \\
40-49 \text { years } \\
50-59 \text { years } \\
>60 \text { years }\end{array}$ & $\begin{array}{r}2 \\
16 \\
28 \\
17 \\
1\end{array}$ & $\begin{array}{r}3.1 \\
25.0 \\
43.8 \\
26.6 \\
1.6\end{array}$ & 179 \\
\hline $\begin{array}{l}\text { Employment status change } \\
\text { Yes } \\
\text { No }\end{array}$ & $\begin{array}{l}14 \\
50\end{array}$ & $\begin{array}{l}21.9 \\
78.1\end{array}$ & \\
\hline $\begin{array}{l}\text { Current employment status } \\
\text { Employed full-time } \\
\text { Employed part-time } \\
\text { Unemployed } \\
\text { Other }\end{array}$ & $\begin{array}{r}44 \\
7 \\
2 \\
11\end{array}$ & $\begin{array}{r}68.8 \\
10.9 \\
3.1 \\
17.2\end{array}$ & \\
\hline $\begin{array}{l}\text { Location } \\
\text { Australia } \\
\text { Canada } \\
\text { China } \\
\text { Colombia } \\
\text { Finland } \\
\text { Malta } \\
\text { Mexico } \\
\text { Monaco } \\
\text { New Zealand } \\
\text { Singapore } \\
\text { Sweden } \\
\text { United Kingdom } \\
\text { United States of America } \\
\text { Unknown } \\
\text { Vietnam }\end{array}$ & $\begin{array}{r}5 \\
4 \\
1 \\
1 \\
1 \\
1 \\
2 \\
1 \\
1 \\
2 \\
2 \\
1 \\
39 \\
2 \\
1\end{array}$ & $\begin{array}{r}7.8 \\
6.3 \\
1.6 \\
1.6 \\
1.6 \\
1.6 \\
3.1 \\
1.6 \\
1.6 \\
3.1 \\
3.1 \\
1.6 \\
60.9 \\
3.1 \\
1.6\end{array}$ & $\begin{array}{r}\text { Table } 2 . \\
\text { Sample descriptive } \\
\text { statistics }\end{array}$ \\
\hline
\end{tabular}

Respondents were predominantly male $(n=50,78.1 \%)$, and the average age was 45 years. 14 respondents' employment status had changed due to the COVID-19 pandemic, but the majority of respondents were employed full-time $(n=44,68.8 \%)$. Most of the respondents' operations were located in the USA $(n=39,60.9 \%)$. Five respondents were located in Australia, 4 in Canada, 2 locations were unknown, and the remainder represented various countries throughout South America, Europe, and Asia.

\subsection{Spearman correlations and gap analysis}

The mean, SD, and gap for each practice is listed in Table 3. All Spearman correlations (Table 4 ) were positive and statistically significant (at $p<0.01$ ), indicating that at a basic level GBSs have managed effectively. MK12 - marketing and promoting new products or services correlated the highest (0.71) and ranked second for both importance and use (4.83 and 4.43 respectively). Three practices from the maintenance construct (MA15, MA16, and MA17) also correlated highly $(0.66,0.65$ and 0.65 respectively). MA17 - extending credit or postponing 


\begin{tabular}{|c|c|c|c|c|c|c|c|c|c|}
\hline $\begin{array}{l}\text { IHR } \\
35,2\end{array}$ & \multicolumn{5}{|c|}{ Importance } & \multicolumn{2}{|l|}{ Use } & Gap & $p$ value \\
\hline \multirow{6}{*}{180} & HR1 & 12 & 3.81 & 1.99 & 7 & 3.71 & 2.58 & 0.103 & 0.706 \\
\hline & HR2 & 13 & 3.79 & 1.84 & 11 & 3.47 & 2.40 & 0.328 & 0.287 \\
\hline & HR3 & 10 & 3.98 & 1.95 & 8 & 3.64 & 2.50 & 0.345 & 0.214 \\
\hline & HR4 & 5 & 4.36 & 1.96 & 3 & 4.21 & 2.43 & 0.155 & 0.560 \\
\hline & HR5 & 20 & 2.00 & 1.51 & 19 & 2.09 & 1.76 & -0.086 & 0.633 \\
\hline & HR6 & 17 & 2.40 & 1.54 & 18 & 2.17 & 1.52 & 0.224 & 0.359 \\
\hline \multirow{15}{*}{$\begin{array}{l}\text { Table 3. } \\
\text { Practices' rank, mean, } \\
\text { standard deviation, } \\
\text { and gap analysis } \\
\text { results }\end{array}$} & MK7 & 14 & 3.74 & 1.95 & 17 & 2.67 & 1.79 & 1.069 & 0.000 \\
\hline & MK8 & 8 & 4.12 & 2.12 & 14 & 3.10 & 2.07 & 1.017 & 0.000 \\
\hline & MK9 & 9 & 4.12 & 1.86 & 12 & 3.40 & 2.09 & 0.724 & 0.002 \\
\hline & MK10 & 10 & 3.97 & 1.75 & 13 & 3.24 & 1.99 & 0.724 & 0.005 \\
\hline & MK11 & 15 & 3.53 & 2.04 & 15 & 2.83 & 1.96 & 0.707 & 0.008 \\
\hline & MK12 & 2 & 4.83 & 1.87 & 2 & 4.43 & 2.10 & 0.397 & 0.043 \\
\hline & MK13 & 4 & 4.67 & 1.90 & 6 & 3.93 & 2.17 & 0.741 & 0.003 \\
\hline & MA14 & 6 & 4.31 & 1.84 & 4 & 4.21 & 2.20 & 0.103 & 0.674 \\
\hline & MA15 & 11 & 3.93 & 2.07 & 9 & 3.64 & 2.35 & 0.293 & 0.217 \\
\hline & MA16 & 16 & 2.76 & 1.82 & 16 & 2.74 & 2.03 & 0.017 & 0.933 \\
\hline & MA17 & 3 & 4.79 & 1.91 & 1 & 4.62 & 2.15 & 0.172 & 0.445 \\
\hline & GV18 & 19 & 2.21 & 1.64 & 20 & 1.62 & 1.35 & 0.586 & 0.000 \\
\hline & GV19 & 7 & 4.28 & 1.99 & 10 & 3.53 & 2.18 & 0.741 & 0.003 \\
\hline & GV20 & 1 & 4.86 & 1.94 & 5 & 4.05 & 2.27 & 0.810 & 0.002 \\
\hline & \multicolumn{9}{|c|}{$\operatorname{Note}(\mathbf{s}): N=58$} \\
\hline
\end{tabular}

\begin{tabular}{llc}
\hline Practice & Description & Correlation $^{*}$ \\
\hline MK12 & Marketing and promoting new products or services & 0.712 \\
MA15 & Cost cuts by postponing maintenance of the building (cosmetics) & 0.663 \\
MA17 & Extending credit or postponing scheduled payments & 0.650 \\
MA16 & Cost cuts by postponing maintenance to the engineering systems & 0.647 \\
MK8 & Marketing to locals with focus on specific attributes of the location & 0.642 \\
MK7 & Marketing to locals in joint campaigns with local merchants & 0.630 \\
MK9 & Price drop on special offers & 0.629 \\
HR1 & Laying off employees to reduce labor force & 0.629 \\
HR5 & Replacing highly paid employees with new low paid employees & 0.619 \\
GV19 & Industry-wide demand for governmental assistance with current expenses & 0.619 \\
MK13 & Marketing to new segments & 0.601 \\
GV18 & Organized protest against the lack of government support & 0.598 \\
GV20 & Industry-wide demand for a grace period on tax payments & 0.593 \\
HR4 & Freezing pay rates & 0.571 \\
HR3 & Reducing the number of workdays per week & 0.570 \\
MA14 & Cost cuts by limiting services & 0.543 \\
MK10 & Reduce prices & 0.530 \\
MK11 & Marketing to non-locals with specific focus on the location's distinctive features and & 0.502 \\
& relative safety & \\
HR2 & Using unpaid vacation to reduce labor force & 0.439 \\
HR6 & Increased reliance on outsourcing & 0.408 \\
Note(s): $N=58$ & \\
*all correlations are significant at 0.01 & \\
\hline
\end{tabular}

scheduled payments ranked highest for use and third for importance. HR6 - increased reliance on outsourcing received the lowest correlation (0.41) and was third lowest for average 
importance and use (2.40 and 2.17 respectively). HR5 - replacing highly paid employees with low paid employees and GV18 - organized protest against lack of government support were among the lowest for average importance and usage but were mid-table in terms of correlation (0.62 and 0.60, respectively).

Gap analysis revealed statistically significant positive differences (at $p<0.05$ ) for all marketing and government practices; indicating each practices' mean level of use was lower than the mean rating of importance. Gaps in the human resources and maintenance categories were lower in magnitude and not statistically significant. Table 5 lists the marketing and government practices in order of priority value. MK8 - marketing to locals with focus on specific attributes of the location, which ranked 8th for importance and 14th for use generated the highest priority of value (4.19). MK7 - marketing to locals in joint campaigns with local merchants and GV20 - industry-wide demand for a grace period on tax payments also produced high priority values; 4.00 and 3.94 , respectively. The lowest priority value (1.30) was attributed to GV18 - organized protest against the lack of government support which ranked 19th for importance and 20th for use.

\subsection{HCMQ construct validity}

4.2.1 Principal component analysis of practice importance. Table 6 presents the results of the PCA of practice importance, including factor loading, eigenvalues, variance explained, and reliability measures. Four components accounted for $61.92 \%$ of the variance. The reliabilities for all components indicated acceptable levels of internal consistency $(\alpha=0.76-0.87)$. The grouping of practices within each component suggests themes consistent with: (1) marketing and labor efficiency, (2) efficiency and government protest, (3) expenses, and (4) new marketing. The marketing and labor efficiency factor included marketing practices related to price reductions, as well as campaigns geared toward locals and nonlocals. The component also composed of practices concerned with reducing labor costs. The efficiency and government protest factor included human resources and maintenance practices related to reducing overheads, as well as GV18 - organized protest against the lack of government support. The expenses factor included government and maintenance practices pertaining to managing cash flow and expenses. The new marketing factor composed of marketing practices related to new segments and promotion of new products or services. MA15 - cost cuts by postponing maintenance of the building (cosmetics) was removed from the new marketing factor due to an inadequate contribution to internal reliability (Cronbach's $\alpha$ ).

\begin{tabular}{|c|c|c|c|c|c|}
\hline Practice & Description & Importance & Gap & $\begin{array}{l}\text { Priority } \\
\text { value }\end{array}$ & \\
\hline MK8 & $\begin{array}{l}\text { Marketing to locals with focus on specific attributes of the } \\
\text { location }\end{array}$ & 4.12 & 1.017 & 4.190 & \\
\hline MK7 & Marketing to locals in joint campaigns with local merchants & 3.74 & 1.069 & 3.998 & \\
\hline GV20 & Industry-wide demand for a grace period on tax payments & 4.86 & 0.810 & 3.937 & \\
\hline MK13 & Marketing to new segments & 4.67 & 0.741 & 3.460 & \\
\hline GV19 & $\begin{array}{l}\text { Industry-wide demand for governmental assistance with } \\
\text { current expenses }\end{array}$ & 4.28 & 0.741 & 3.171 & \\
\hline MK9 & Price drop on special offers & 4.12 & 0.724 & 2.983 & \\
\hline MK10 & Reduce prices & 3.97 & 0.724 & 2.874 & \\
\hline MK11 & $\begin{array}{l}\text { Marketing to nonlocals with specific focus on the location's } \\
\text { distinctive features and relative safety }\end{array}$ & 3.53 & 0.707 & 2.496 & $\begin{array}{r}\text { Table } 5 . \\
\text { Priority ranking for } \\
\text { crisis manaoment }\end{array}$ \\
\hline MK12 & Marketing and promoting new products or services & 4.83 & 0.397 & 1.918 & \\
\hline GV18 & Organized protest against the lack of government support & 2.21 & 0.586 & 1.295 & $\begin{array}{r}\text { practices with } \\
\text { statistically significant }\end{array}$ \\
\hline \multicolumn{5}{|c|}{$\operatorname{Note}(\mathbf{s}): N=58$} & \\
\hline
\end{tabular}




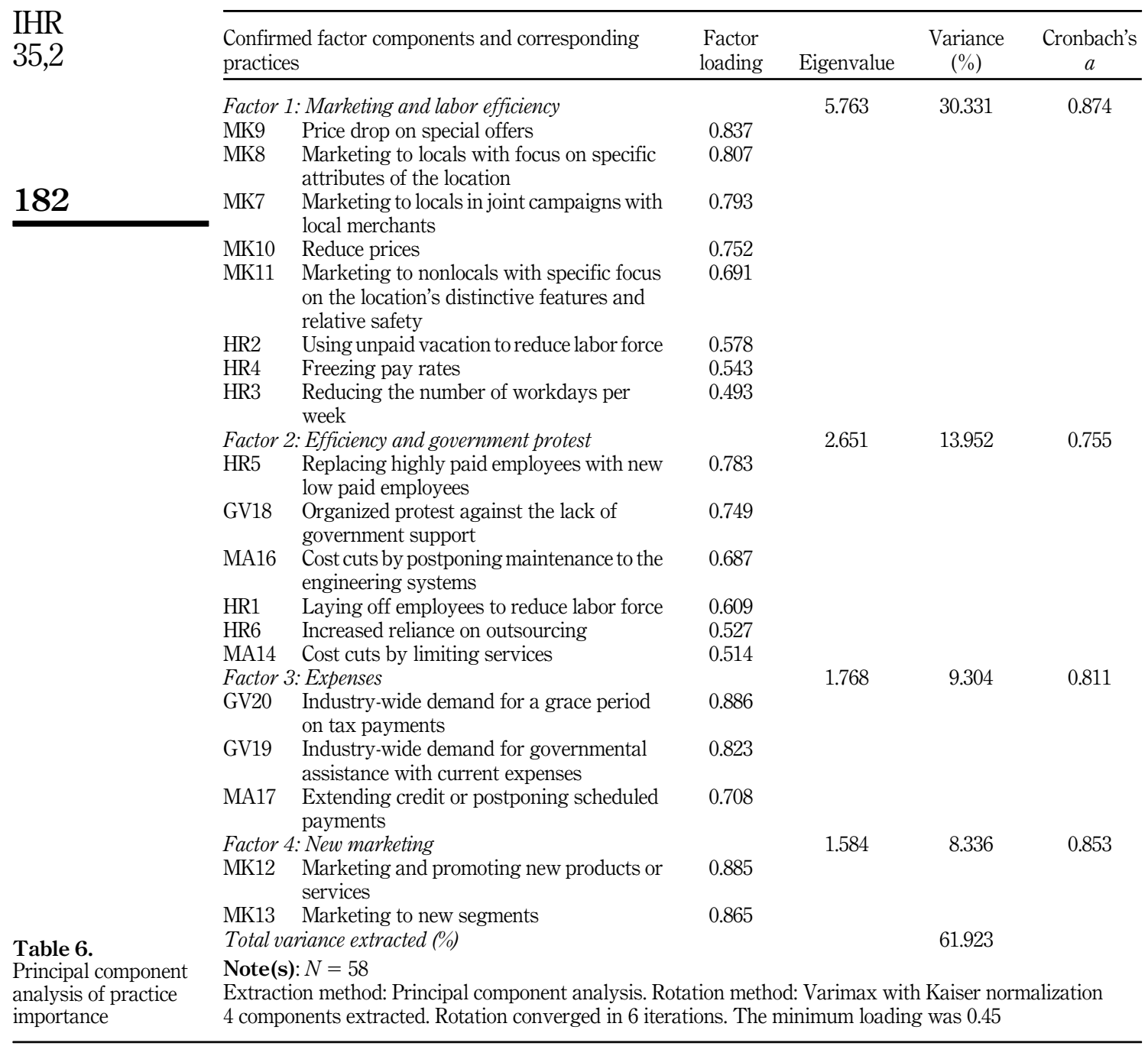

4.2.2 Principal component analysis of practice use. Results of the PCA of practice use are presented in Table 7. Four components accounted for $58.62 \%$ of the variance. The reliabilities for all components indicated reasonable levels of internal consistency $(\alpha=0.65-0.83)$. The grouping of practices within each component suggests themes consistent with: (1) marketing, (2) efficiency and government protest, (3) labor efficiency and price reductions, and (4) expenses. The marketing factor included all practices under the original HCMQ marketing construct, except MK10 - reduce prices. The efficiency and government protest factor included the same practices (those related to reducing overheads) as the corresponding factor for the PCA of practice importance with the addition of practice MA15 - cost cuts by postponing maintenance to building (cosmetics). The labor efficiency and price reductions factor comprised the same three practices concerned with reducing labor costs included in the 


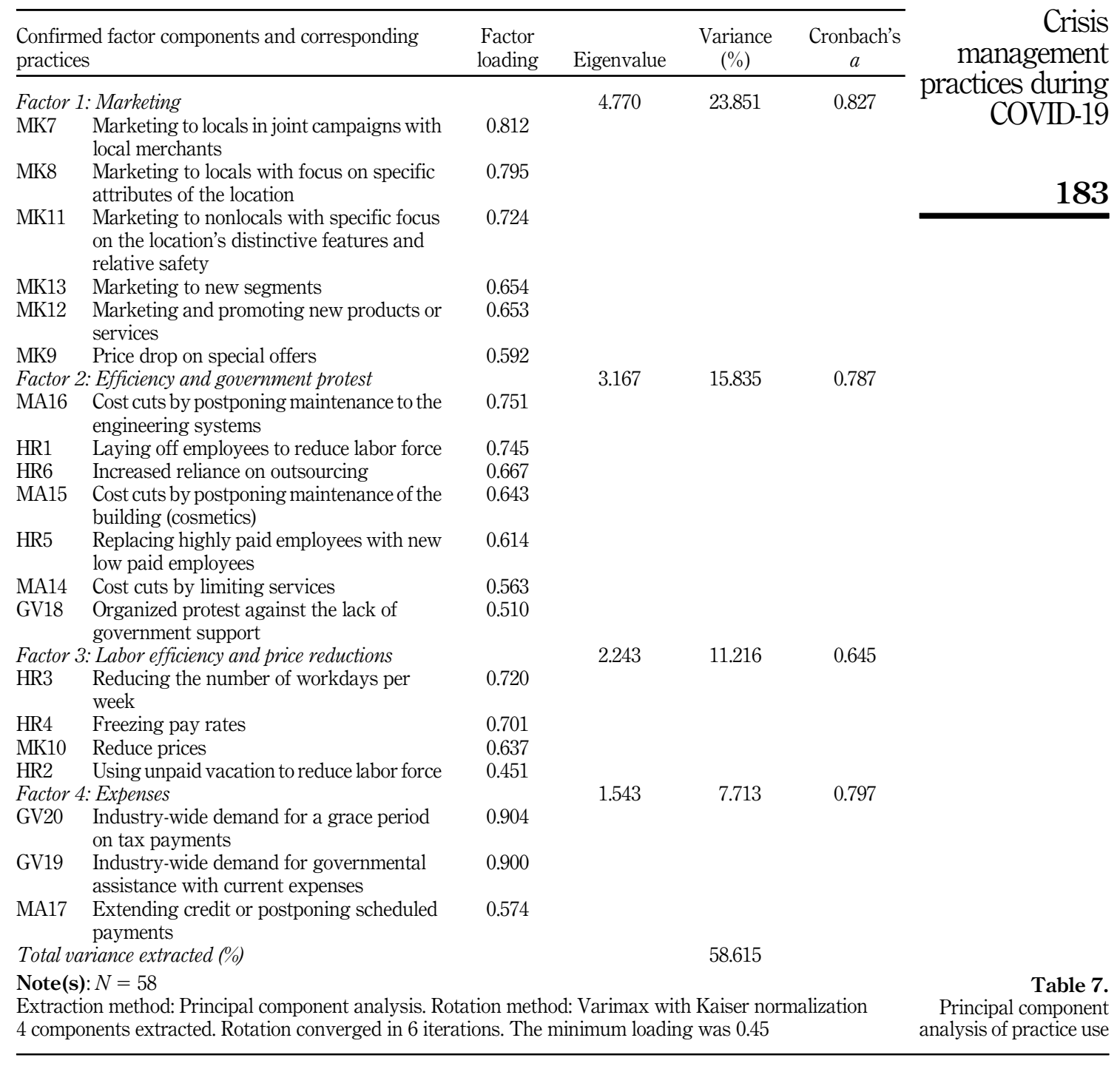

marketing and labor efficiency factor from the PCA of practice importance in addition to marketing practice MK10 - reduce prices. The expenses factor paralleled the third factor of the PCA of practice importance, consisting of factors related to cash flow management.

4.2.3 Principal component analysis of practice effectiveness. Table 8 presents results of the PCA of practice effectiveness. $56.85 \%$ of the variance was explained by four components representing themes of: (1) marketing, (2) holistic, (3) expenses, and (4) labor efficiency and limiting services. Marketing practices related to price reductions and targeted campaigns for locals and nonlocals characterized the marketing factor, which also had strong internal consistency $(\alpha=0.84)$. The holistic factor resembled no apparent theme and included practices from all four original $\mathrm{HCMQ}$ constructs. It also lacked internal consistency 
IHR
35,2

Confirmed factor components and corresponding practices

Factor

loading

Factor 1: Marketing

MK9 Price drop on special offers

0.795

MK11 Marketing to nonlocals with specific focus

0.785

on the location's distinctive features and

184

MK7 Marketing to locals in joint campaigns with local merchants

MK8 Marketing to locals with focus on specific attributes of the location

MK10 Reduce prices

Factor 2: Holistic

MA16 Cost cuts by postponing maintenance to the engineering systems

MA15 Cost cuts by postponing maintenance of the building (cosmetics)

HR5 Replacing highly paid employees with new $\quad 0.655$ low paid employees

GV18 Organized protest against the lack of 0.634 government support

MK12 Marketing and promoting new products or $\quad-0.574$ services

MK13 Marketing to new segments

Factor 3: Expenses

GV20 Industry-wide demand for a grace period on tax payments

0.783

0.754

0.676

0.783

$2.994 \quad 14.970 \quad 0.425$

0.702

0.655

$-0.451$

0.884

$2.288 \quad 11.442$

0.818

GV19 Industry-wide demand for governmental

0.869

MA17 Extending credit or postponing scheduled

0.703 payments

Factor 4: Labor efficiency and limiting services

HR2 Using unpaid vacation to reduce labor force

0.768

$\begin{array}{lll}\text { MA14 } & \text { Cost cuts by limiting services } & 0.657 \\ \text { HR3 } & \text { Reducing the number of workdays per } & 0.643\end{array}$

HR3 Reducing the number of workdays per

0.523

HR1 Laying off employees to reduce labor force

Total variance extracted (\%)

Table 8.

Principal component analysis of practice effectiveness
Note(s): $N=58$

Extraction method: Principal component analysis. Rotation method: Varimax with Kaiser normalization 4 components extracted. Rotation converged in 5 iterations. The minimum loading was 0.45

( $\alpha=0.43$ ), so further assessment using this factor may be unreliable. The expenses factor consisted of the same practices as the corresponding expenses factors of the PCAs of practice importance and use, with the reliability measure indicating strong internal consistency $(\alpha=0.82)$. The labor efficiency and limiting services factor included practices related to cutting costs by reducing the labor force and the number of hours worked, as well as limiting services. The factor produced a reasonable level of internal consistency $(\alpha=0.64)$. Two practices (HR6 - increased reliance on outsourcing and HR4 - freezing pay rates) did not meet the loading cut-off value (0.45) and were excluded from final analysis.

\subsection{Two-sample t-tests}

Of the 58 respondents, 35 indicated that their operation had a formal crisis response plan in place prior to the COVID-19 pandemic. The difference between the mean effectiveness of 
those that had a plan (CRISP $=1)$ and those that did not (CRISP $=0)$ was marginal $(311.17$ and 323.00 respectively), and the difference was not statistically significant $(\phi=0.74) ; 34$ of the 58 respondents stated that their operation had experienced a crisis before. The difference between the mean effectiveness of those that had previously experienced a crisis (CRISE $=1$ ) and those that had not (CRISE $=0$ ) was 66.36 (343.32-276.96), and the difference was statistically significant at $p<0.05(0.04)$. Cohen's $d$ was 0.55 , indicating a medium effect size (Cohen, 1988).

\subsection{Future}

For responses to the question "How confident are you that your operation will recover from COVID-19?", 58 respondents $(90.63 \%)$ were either "Extremely confident" $(n=30)$ or "Moderately confident" ( $n=28)$. Table 9 presents counts and percentages for respondents' beliefs regarding customers' future expenditures on travel and leisure activities. Most respondents indicated that they believed customer spending will be reduced to some extent for all categories, with only a small number of respondents indicating that customers would not reduce their spending at all. International travel and live entertainment were most concerning among respondents, with $39.06 \%$ and $25 \%$, respectively indicating that they believed customers would reduce their spending "a great deal" in these categories.

Table 10 ranks future strategies (by mean) for the question "Reflecting upon the COVID-19 pandemic, please rate how likely you are to implement the following strategies with respect to the future of your operation". The strategy that respondents indicated that they would most likely implement was F3 - Revise facility hygiene standards and practices (mean $=4.75$ ), followed by F4 - Revise employee hygiene standards and practices. The strategy that ranked lowest was F7 - Enforce a smoke-free policy throughout the facility/place of work (mean $=3.02$ ).

Table 11 presents the principal component analysis of future strategies, including reliability measures. The EFA produced three components accounting for $81.21 \%$ of the variance. Groupings of the strategies within factors suggested they represent: (1) prevention, (2) hygiene, and (3) use public assisted funds. The prevention factor displayed strong internal consistency $(\alpha=0.86)$ and comprises strategies addressing crisis preparedness (creation of a crisis management team and creation/revision of a plan), the implementation of a tool to monitor customer satisfaction with respect to COVID-19, and enforcement of employee PPE ensembles. The hygiene factor also exhibited strong internal consistency $(\alpha=0.83)$ and included strategies related to enhancing hygiene. The use of public assisted funds measure (F12) loaded individually, and was kept as part of analysis due to both theoretical value and quantitative value, in its relevant contribution to variance explained.

\begin{tabular}{|c|c|c|c|c|c|c|c|c|c|c|}
\hline \multirow[b]{2}{*}{ Travel/Leisure category } & \multicolumn{2}{|c|}{ None at all } & \multicolumn{2}{|c|}{ A little } & \multicolumn{2}{|c|}{$\begin{array}{l}\text { A moderate } \\
\text { amount }\end{array}$} & \multicolumn{2}{|c|}{ A lot } & \multicolumn{2}{|c|}{ A great deal } \\
\hline & $\%$ & $N$ & $\%$ & $N$ & $\%$ & $N$ & $\%$ & $N$ & $\%$ & $N$ \\
\hline Gambling & 7.81 & 5 & 35.94 & 23 & 42.19 & 27 & 10.94 & 7 & 3.13 & 2 \\
\hline Visitation & 7.81 & 5 & 23.44 & 15 & 43.75 & 28 & 23.44 & 15 & 1.56 & 1 \\
\hline Dining & 10.94 & 7 & 23.44 & 15 & 45.31 & 29 & 17.19 & 11 & 3.13 & 2 \\
\hline Live entertainment & 6.25 & 4 & 14.06 & 9 & 23.44 & 15 & 31.25 & 20 & 25.00 & 16 \\
\hline Sports & 18.75 & 12 & 25.00 & 16 & 34.38 & 22 & 10.94 & 7 & 10.94 & 7 \\
\hline Hotel stays & 9.38 & 6 & 25.00 & 16 & 39.06 & 25 & 25.00 & 16 & 1.56 & 1 \\
\hline Domestic travel & 9.52 & 6 & 25.40 & 16 & 42.86 & 27 & 22.22 & 14 & 0.00 & 0 \\
\hline International travel & 1.56 & 1 & 10.94 & 7 & 14.06 & 9 & 34.38 & 22 & 39.06 & 25 \\
\hline
\end{tabular}

Table 9. Response data for "As the pandemic recedes, to what extent do you think customers will reduce their spending toward. .."

Note(s): $N=64$ 


\begin{tabular}{lllr}
\cline { 2 - 3 } IHR & Strategy & Description & Mean \\
\cline { 2 - 4 } & F3 & Revise facility hygiene standards and practices & 4.75 \\
& F4 & Revise employee hygiene standards and practices & 4.70 \\
& F9 & Enforce PPE ensembles for employees (e.g. some combination of gloves, a gown, a face & 4.34 \\
& & mask and/or a face shield, or goggles) & 4.28 \\
$\mathbf{1 8 6}$ & F1 & Create/Revise Crisis Management Plan & 4.28 \\
& F6 & Invest in new technologies to enhance hygiene & 4.02 \\
& F5 & Invest more in employee health and wellness strategies & 4.00 \\
& F2 & Implement a tool to assess customer's satisfaction with response to COVID-19 & 3.89 \\
& F10 & Create a Crisis Management Team & 3.50 \\
Table 10. & F12 & Use public assisted funds (e.g. bailout, tax breaks) & 3.34 \\
Ranking of future & F8 & Install physical barriers, such as clear plastic sneeze guards, where feasible & 3.27 \\
strategies by mean & Note(s): $N=64$ & 3.02 \\
\hline
\end{tabular}

Table 11

Principal component analysis of future strategies

\begin{tabular}{|c|c|c|c|c|}
\hline $\begin{array}{l}\text { Confirmed factor components and corresponding } \\
\text { practices }\end{array}$ & $\begin{array}{l}\text { Factor } \\
\text { loading }\end{array}$ & Eigenvalue & $\begin{array}{l}\text { Variance } \\
(\%)\end{array}$ & $\begin{array}{c}\text { Cronbach's } \\
a\end{array}$ \\
\hline \multicolumn{2}{|l|}{ Factor 1: Prevention } & \multirow[t]{4}{*}{4.265} & \multirow[t]{4}{*}{53.312} & \multirow[t]{5}{*}{0.864} \\
\hline Create a Crisis Management Team & 0.993 & & & \\
\hline F1 Create/Revise Crisis Management Plan & 0.848 & & & \\
\hline $\begin{array}{l}\text { F11 Implement a tool to assess customers } \\
\text { satisfaction with respect to COVID-19 }\end{array}$ & 0.632 & & & \\
\hline F9 Enforce PPE ensembles for employees & 0.486 & & & \\
\hline \multicolumn{2}{|l|}{ Factor 2: Hygiene } & \multirow[t]{4}{*}{1.209} & \multirow[t]{4}{*}{15.113} & \multirow[t]{4}{*}{0.828} \\
\hline $\begin{array}{l}\text { F4 Revise employee hygiene standards and } \\
\text { practices }\end{array}$ & -0.997 & & & \\
\hline $\begin{array}{l}\text { F3 Revise facility hygiene standards and } \\
\text { practices }\end{array}$ & -0.950 & & & \\
\hline $\begin{array}{l}\text { F6 Invest in new technologies to enhance } \\
\text { hygiene }\end{array}$ & -0.508 & & & \\
\hline \multicolumn{2}{|l|}{ Factor 3: Use public assisted funds } & \multirow{3}{*}{1.022} & \multirow{2}{*}{12.780} & \multirow[t]{3}{*}{ - } \\
\hline $\begin{array}{l}\text { F12 Use public assisted funds (e.g. bailout, tax } \\
\text { breaks) }\end{array}$ & 1.002 & & & \\
\hline \multicolumn{2}{|l|}{ Total variance extracted (\%) } & & 81.206 & \\
\hline \multicolumn{5}{|c|}{$\begin{array}{l}\text { Note(s): } N=64 \\
\text { Extraction method: Principal component analysis. Rotation method: Oblimin with Kaiser normalization } \\
3 \text { components extracted. Rotation converged in } 15 \text { iterations. The minimum loading was } 0.45\end{array}$} \\
\hline
\end{tabular}

\section{Discussion}

This study is extremely timely given the disruption to the gambling industry and wider hospitality sector as a result of the COVID-19 pandemic. The findings reveal important considerations with respect to crisis management for GBSs as they navigate the current environment and the path ahead as the pandemic abates. The results from the Spearman correlations imply GBSs have acted coherently; utilizing the practices they believe to be important. This finding is in accordance with prior studies employing the HCMQ (Israeli and Reichel, 2003; Israeli 2007; Israeli et al., 2011, 2018; Perl and Israeli, 2011). In attempts to provide further insight, prior works compared the ranks of each practice's mean importance and use. While this study also presents rankings, the methodology is advanced by the 
introduction of gap analysis. Gap analysis provided an efficient way to identify discrepancies between each practices' importance and use. It is of note that all marketing and government practices had meaningful positive gaps, suggesting some obstacle or aversion to the utilization of practices up to their corresponding level of importance. Marketing practices may seem less valuable to gambling businesses, given travel restrictions, physical distancing and, other COVID-19 preventative measures, and GBSs might view governmental assistance as something that is out of their control. The human resources and maintenance practices, meanwhile, may be more easily manipulated and provide immediate cash flow relief.

The calculation of priority values provides methodological and practical benefits allowing for the prioritization of under-utilized crisis management practices (RQ1). Consider practice MK7 (Marketing to locals in joint campaigns with local merchants): its correlation is high and statistically significant, and it ranks low for importance and use (14th and 17th, respectively). Given MK7's low rank for importance, it could easily be overlooked. However, its priority value is the second highest (3.99), indicating the practice might not be utilized to its full potential. With respect to the COVID-19 pandemic and the practices identified in Table 5 , GBSs might consider re-evaluating their domestic marketing strategies and bolster collaborative efforts with respect to lobbying for governmental assistance. Given restrictions related to international and even domestic travel, marketing to locals (MK7 and MK8) and identifying new segments (MK13) could help operators weather the storm. In light of COVID-19, more risk-tolerant younger generations appear as an opportunity segment that could provide near term value but could also be nurtured into a longer-term strategic advantage (Arpin et al., 2020). In the US, airlines, and to some extent hotels, have emerged as winners in their pursuit for bailout funds (Woodyard, 2020), but some gambling operators have been left behind. For example, small casinos with under 500 employees have been ineligible for aid under the US Paycheck Protection Program (Stradbrooke, 2020).

With regard to RQ2, the results from the PCAs of practice importance, use, and effectiveness revealed factors that only partially adhere to the original constructs of the HCMQ. For each of these three areas, marketing was a consistent theme. The marketing factor for both the PCAs of practice use and effectiveness comprises marketing practices entirely with strong reliabilities $(\alpha \mathrm{s}>0.80)$. Additionally, the PCA of practice importance revealed two factors with marketing themes, both with strong internal consistency $(\alpha \mathrm{s}>0.80)$. The marketing and labor efficiency factor was predominantly marketing orientated (5 out of the 8 items were marketing practices), and the new marketing factor comprised of two marketing practices. While the marketing practices appeared to cluster and reveal a consistent theme, results from the gap analysis suggest marketing as an area GBSs may be able to optimize once they have exhausted more immediately impactful strategies.

Efficiency emerged as the primary theme in the efficiency and government protest factor for the PCAs of practice importance and use. GBSs recognize the importance of cash flow management and seek out cost efficiencies during this time of crisis. Efficiency also emerged as a theme in the holistic factor of PCA of practice effectiveness, including cost reduction measures by postponing maintenance (MA15 and MA16) and replacing highly paid employees with new low paid employees (HR5). Notably, the factor contained two negatively loaded marketing practices, suggesting marketing practices may serve as an alternative approach to cost reduction measures.

The original HCMQ "government" construct also materialized as a somewhat consistent theme in this study. The expenses factor comprised two of the three government practices (GV19 - Industry-wide demand for governmental assistance with current expenses and GV20 - Industry-wide demand for a Grace period on tax payments) and included MA17 Extending credit or postponing scheduled payments. The expenses factor exhibited strong internal consistency $(\alpha=0.80-0.82)$ and appeared as the third factor for the PCAs of practice importance and effectiveness, and fourth factor for the PCA of practice use. The replacement 
IHR

35,2

188 of GV18 - Organized protest against the lack of government support with MA17 is somewhat logical, and implies GBSs acknowledge ways to reduce or gain assistance with expenses.

This study concludes that the original HCMQ's constructs are not supported in totality. Here, three themes of marketing, efficiency, and expenses emerge across all three PCAs. Human resources and maintenance practices clustered together, but not distinctly, and here GBSs seemed to group practices around a broader theme of efficiency. Two of the three practices from the government construct were recognized consistently, although these were accompanied by a maintenance practice that depicted a theme more aligned with expenses in general. Marketing and the broader theme of efficiency, as opposed to more distinct human resources and maintenance themes, were also identified in prior works employing the HCMQ in the Israeli and Indian hospitality sectors (Israeli and Reichel, 2003; Israeli et al., 2011). Marketing efforts can help bolster both short- and long-term business volumes. Moreover, cost cutting and cost management strategies can provide immediate cash flow relief.

The influence of crisis preparedness showed contrary outcomes. While the existence of a formal crisis response plan had no bearing on effectiveness (RQ3), those GBSs with prior crisis experience exhibited significantly higher scores (RQ4). At face value, these results might suggest formal contingency plans provide no managerial advantage. Alternatively, the extraordinary nature of the COVID-19 pandemic may have made the application of any plan obsolete. Here, prior crisis experiences equipped managers with an enhanced ability to put their beliefs into action. Furthermore, just $6 \%$ of respondents (2/34) specified the type of their prior crisis experience as "biological", suggesting that lessons are learned irrespective of the nature of the crisis. As gambling and hospitality operators continue to navigate COVID-19, potential strategies to consider may be (1) identifying internal personnel with prior crisis experience and (2) communicate, collaborate, and share knowledge with industry peers who have prior crisis management experience.

With regard to RQ5 and respondents' views of recovery from COVID-19, the large majority of GBSs were confident that their operation would recover. There were, however, concerns about changes in consumer spending patterns (RQ6). These concerns support the promotion of the same kind of initiatives identified in the gap analysis and factor analyses. Namely, as the pandemic recedes, GBSs are concerned that spending on international travel will be reduced a great deal. This emphasizes the importance of outreach to local markets and the identification of new potential target markets, particularly for the myriad gambling operators within destination markets, such as Las Vegas and Macau, who have been innocently reliant on tourism (Travel Weekly Asia, 2019). Moreover, in recent years, gambling-related hospitality has seen a shift away from a singular focus on gambling, and an increased presence of integrated resorts with a wide range of offerings (Eadington, 1999). However, should this hypothesized shift in consumer spending materialize, operators may need to transform and allocate resources to areas that show the greatest potential for returns. A recent survey assessing consumer attitudes with respect to casino visitation during COVID-19 suggests that customers may feel more comfortable on the casino floor, in hotel rooms, and in restaurants, but less comfortable in spas, nightclubs, and other entertainment venues (Arpin et al., 2020). Gambling-related hospitality businesses should strive to communicate the relative safety of these more favorable environments. Moreover, given the higher comfort level among younger generations to revisit casino resorts amidst the pandemic, operators must find ways to make these offerings more relevant to this bourgeoning audience.

In addressing RQ7, the factor analysis of future strategies revealed findings reflective of the quickly evolving understanding of the virus over time. At the time the survey was administered (early May 2020) there were significant concerns regarding fomite transmission (via surface touching), and this is reflected in the hygiene factor. Additionally, the hygiene strategy of Install physical barriers, such as clear plastic sneeze guards, where feasible, was 
ranked 11th out of the total 12 strategies and did not meet the cut-off value for inclusion in the factor analysis. At the time of this writing, aerosol transmission has gained substantial attention, with mask wearing and physical barriers becoming highly recommended or even mandatory in many jurisdictions (Al Jazeera, 2020). The formation of COVID-19 task forces will help GBSs' keep abreast of information regarding preventative measures. But internal and external communication should not be overlooked. For example, in casinos and other gambling-related hospitality businesses, regular training periods could be scheduled to ensure personnel in both front-of-house and back-of-house departments are implementing and adhering to the most up-to-date policies. For other GBSs', such as slot machine manufacturers and other suppliers, collaboration with local regulators could help ensure compliance with fast-evolving preventative measures and support innovation of new products and services to address pandemic-induced challenges. Moreover, strategies F1 Create/Revise Crisis Management Plan (that ranked 4th) and F2 - Create a Crisis Management Team (that ranked 8th) were included in the prevention factor. Given that prior crisis experience appears to indicate more effective crisis management, however, management finding themselves with limited resources due to the pandemic should consider prioritizing the creation of a crisis management team over the creation/revision of a formal plan.

\section{Limitations and future research}

This research is not without limitation. Due to the cross-sectional design of the study, data were collected at a single point in time and therefore no inference to causality can be made. However, an attempt was made to evaluate pre- and post-crisis phases with the research instrument. The sampling procedure garnered a specific population of GBSs (members and faculty of the EDP), with approximately $30 \%$ of the sampled population being represented by this research. While globally diverse, the findings come from a relatively small sample in a niche population, and cannot be generalized to the worldwide population of GBSs or management in other hospitality sectors. Moreover, the pandemic has reached varying degrees of severity at different times, in different locales, which may have created unexplained variation in our globally collected response data.

The 20 crisis management practices included in the adapted version of the HCMQ used in this study were drawn from prior literature. This could explain why construct validity within the original HCMQ themes was not supported. Borrowing from prior literature may have also prevented the identification of specific COVID-19 crisis management themes, by overlooking practices that could be common among GBSs in this unique hospitality setting. In prior works employing IPA, some researchers develop a specific set of attributes, while others reuse attributes from previous studies (Lai and Hitchcock, 2015). Here, reapplication of the HCMQ attributes was favorable, allowing for (1) timely implementation and execution of the study, (2) a contribution to literature in potential validation of the tool, and (3) promotion of the future application of the tool to other crises and businesses. Future research on COVID-19 crisis management in gambling-related hospitality businesses should consider constructing attributes based on prior interviews with knowledgeable stakeholders and then validating these with a small sample before distributing to a wider population. Furthermore, in terms of data collection, administration of the HCMQ at a single time-point produces risk of a consistency motif (in which respondents tend to provide consistent answers across items) (Lai and Hitchcock, 2015). Therefore, researchers should explore a two-phase administration of the HCMQ to avoid influence from the rating of importance on the rating of use and bolster reliability of the data.

There are ongoing debates and differences concerning data collection methods and analytical procedures with respect to IPA. For example, the use of I-P mapping and whether 
IHR

35,2

or not factor analysis should be employed are among several queries that have emerged from reviews of the literature (see, e.g. Lai and Hitchcock, 2015). In the present study, the methodology and analysis protocol proposed by the HCMQ developers was followed to facilitate comparison with prior HCMQ work, and was deemed appropriate given the intentional design of the HCMQ to assess crisis management in situations similar to the current pandemic environment. Future research can further the additional methodological contributions made in this work, applying gap analysis to the HCMQ data.

Finally, it is unknown what influence GBSs' crisis management capabilities have on longer term firm performance and positioning. As identified in the study preregistration (https:/osf.io/hej3y), the current study did attempt to investigate this relationship by employing regression analysis with confidence in recovery as the dependent variable, however, attenuated ranges in the confidence in recovery variable rendered the analysis impossible. More widespread data collection may gather more varied responses.

\section{Funding statements}

During the past five years, International Gaming Institute has received research funding from MGM Resorts International, Wynn Resorts Ltd, Las Vegas Sands Corporation, Caesars Entertainment Corporation, Ainsworth Game Technology, US-Japan Business Council, State of Nevada, Knowledge Fund and State of Nevada Department of Health and Human Services. IGI runs the triennial research-focused International Conference on Gambling and Risk Taking, whose sponsors include industry, academic and legal/regulatory stakeholders in gambling. A full list of sponsors for the most recent conference can be found at https://www. unlv.edu/igi/conference/17th/sponsors.

During the past five years, Kasra Ghaharian has received funding from the Nevada Department of Health and Human Services for research on problem gambling.

During the past five years, Brett Abarbanel has received funding from the Manitoba Gambling Research Program, GP Consulting, US-Japan Business Council, Wynn Las Vegas, Victoria Responsible Gambling Foundation, Connecticut Council on Problem Gambling, Bermuda Casino Gambling Commission, the States of Nevada and California, Canadian Partnership for Responsible Gambling, iDevelopment and Economic Association, GLG Consulting, Majestic Star Casinos, MGM Resorts International, ProPress Germany and Caesars Entertainment. Dr Abarbanel has received reimbursement for travel from Association Cluster Sport International, Kansspelautoriteit, Gamification Group (Finland), British Columbia Lottery Corporation, International Association of Gaming Advisors, GambleAware, Las Vegas Convention and Visitors Authority, Ultimate Media Ventures, Canadian Partnership for Responsible Gambling, IGT Latin America, University of Salford and National Collegiate Athletic Association (USA). During the time period, Dr Abarbanel was a member of the Singapore National Council on Problem Gambling International Advisory Panel, for which she was reimbursed for her time.

Marta Soligo has no outside funding to report.

During the past five years, Dr Bernhard has been funded by the US-Japan Business Council, Wynn Resorts, Atomic 47/ePlata Banking, Las Vegas Sands, the Nevada Department of Health and Human Services Governor's Advisory Panel on Problem Gambling, the State of Nevada Knowledge Fund and MGM Resorts International. He has received travel and/or honoraria for presenting his research in more than two dozen countries.

\section{References}

Aderighi, M. and Cento, A. (2004), "European airlines conduct after September 11", Journal of Air Transport Management, Vol. 10 No. 2, pp. 97-107, doi: 10.1016/S0969-6997(03)00053-X. 
Al Jazeera, N.A. (2020), "Which countries have made wearing face masks compulsory?", 17 August, available at: https://www.aljazeera.com/news/2020/04/countries-wearing-face-maskscompulsory-200423094510867.html (accessed 19 August 2020).

Arnold, W. (1980), Crisis Communication, Gorsuch Scarisbrook, Dubuque, IA.

Arpin, R., Bernhard, B., Abarbanel, A. and Ghaharian, K. (2020), "Casinos play their next hand", available at: https:/advisory.kpmg.us/content/dam/advisory/en/pdfs/2020/casinos-play-theirnext-hand.pdf (accessed 31 July 2020).

Barton, L. (1994), “Crisis Management: preparing for and managing disasters", Cornell Hotel and Restaurant Administration Quarterly, Vol. 35 No. 2, pp. 59-65, doi: 10.1177/001088049403500219.

Booth, S. (1993), Crisis Management Strategy, Competition and Changes in Modern Enterprises, Routledge, London.

Caplan, G. (1970), "The theory and practice of mental health consultation", American Behavioral Scientist, Vol. 4 No. 1, p. 133, available at: https://doi.orf/10.1177/000276427001400133.

Center for Open Science (2020), "Best practices - OSF guides”, available at: https://help.osf.io/hc/en-us/ categories/360001530634-Best-Practices (accessed 17 June 2020).

Centers for Disease Control and Prevention (2020a), "Social Distancing: keep a safe distance to slow the spread”, available at: https://www.cdc.gov/coronavirus/2019-ncov/prevent-getting-sick/ social-distancing.html (accessed 31 July 2020).

Centers for Disease Control and Prevention (2020b), "Considerations for travelers-coronavirus in the US”, available at: https:/www.cdc.gov/coronavirus/2019-ncov/travelers/travel-in-the-us.html (accessed 31 July 2020).

Chang, Y., Yeh, C. and Wua, P. (2018), "Evaluating airline crisis management performance: the cases of flights GE222 and GE235 crash accidents", Journal of Air Transport Management, Vol. 70, pp. 62-72, doi: 10.1016/j.jairtraman.2018.04.017.

Cherney, M. (2020), "Casinos shut by coronavirus get a glimpse of the future in Macau”, Wall Street Journal, Vol. 26 March, available at: https://www.wsj.com/articles/casinos-shut-by-coronavirusget-a-glimpse-of-the-future-in-macau-11585280952 (accessed 31 July 2020).

Cohen, J. (1988), Statistical Power Analysis for the Behavioral Sciences, Routledge, New York, NY.

Duke, C.R. and Persia, M.A. (1996), "Performance-importance analysis of escorted tour evaluations", Journal of Travel and Tourism Marketing, Vol. 5 No. 3, pp. 207-223, doi: 10.1300/J073v05n03_03.

Eadington, W.R. (1999), “The economics of casino gambling”, Journal of Economic Perspectives, Vol. 13 No. 3, pp. 173-192, doi: 10.1257/jep.13.3.173.

Faulkner, B. (2001), "Towards a framework for tourism disaster management", Tourism Management, Vol. 22 No. 2, pp. 135-147, doi: 10.1016/S0261-5177(00)00048-0.

Field, A. (2013), Discovering Statistics Using IBM SPSS Statistics, Sage, Newcastle upon Tyne.

Gaming Inspection and Coordination Bureau (2020), "Monthly gross revenue from games of fortune", available at: http://www.dicj.gov.mo/web/en/information/DadosEstat_mensal/2020/index.html (accessed 31 July 2020).

Gössling, S., Scott, D. and Hall, C.M. (2020), "Pandemics, tourism and global change: a rapid assessment of COVID-19", Journal of Sustainable Tourism. doi: 10.1080/09669582.2020. 1758708.

Green, C.G., Bartholomew, P. and Murman, S. (2004), "New York Restaurant industry: strategic responses to September 11, 2001”, Journal of Travel and Tourism Marketing, Vol. 15 Nos 2-3, pp. $63-79$, doi: 10.1300/J073v15n02_04.

Harper, D. (2019), Hurricane Irene a disaster for Atlantic City casinos, which were down about 20 percent in August, The Press of Atlantic City, 19 June, available at: https://pressofatlanticcity. $\mathrm{com} /$ news/local/hurricane-irene-a-disaster-for-atlantic-city-casinos-which-were-down-about-20percent-in/article_a22be564-db11-11e0-b5d2-001cc4c002e0.html (accessed 31 July 2020). 
IHR

35,2

Heath, R. (1998), Crisis Management for Managers and Executives, Financial Times Publishing, London.

Henderson, J.C. and Ng, A. (2004), "Responding to crisis: severe acute respiratory syndrome (SARS) and hotels in Singapore", International Journal of Tourism Research, Vol. 6 No. 6, pp. 411-419, available at: https://dx.doi.org/10.1002\%2Fjtr.505.

Hong, J. and Wei, D. (2020), "Casino shares surge after easing of Macau travel restrictions", Bloomberg, 13 July, available at: https://www.bloomberg.com/news/articles/2020-07-13/macau-casino-hopesbrighten-as-china-lifts-quarantine-rules (accessed 31 July 2020).

Horváth, C. and Paap, R. (2012), "The effect of recessions on gambling expenditures", Journal of Gambling Studies, Vol. 28 No. 4, pp. 703-717, doi: 10.1007/s10899-011-9282-9.

Israeli, A.A. (2007a), "Crisis-management practices in the restaurant industry", International Journal of Hospitality Management, Vol. 26 No. 4, pp. 807-823, doi: 10.1016/j.ijhm.2006.07.005.

Israeli, A.A. (2007b), "Effectiveness and efficiency of managers: are they doing what they can or all they can?”, Tourism Economics, Vol. 13 No. 2, pp. 181-195, doi: 10.5367/000000007780823177.

Israeli, A.A. and Reichel, A. (2003), "Hospitality crisis management practices: the Israeli case", International Journal of Hospitality Management, Vol. 22 No. 4, pp. 353-372, doi: 10.1016/S02784319(03)00070-7.

Israeli, A.A., Mohsin, A. and Kumar, B. (2011), "|Hospitality crisis management practices: the case of Indian luxury hotels", International Journal of Hospitality Management, Vol. 30 No. 2, pp. 367-374, doi: 10.1016/j.ijhm.2010.06.009.

Israeli, A.A., KIrlar-Can, B., Ertas, M., Sel, Z.G. and Tutuncu, O. (2018), "Hospitality crisis management in Turkey: a comparative approach", Tourism Today, No. 17, pp. 27-45.

Kendall, M.G. (1938), “A new measure of rank correlation”, Biometrika, Vol. 30 Nos 1-2, pp. 81-93, doi: 10.1093/biomet/30.1-2.81.

Kim, S.S., Chun, H. and Lee, H. (2005), "The effects of SARS on the Korean hotel industry and measures to overcome the crisis: a case study of six Korean five-star hotels", Asia Pacific Journal of Tourism Research, Vol. 10 No. 4, pp. 369-377, doi: 10.1080/10941660500363694.

Lai, I.K.W. and Hitchcock, M. (2015), "Importance performance analysis in tourism: a framework for researchers", Tourism Management, Vol. 48, pp. 242-267, doi: 10.1016/j.tourman.2014.11.008.

Las Vegas Convention and Visitors Authority (2020a), "McCarran Airport passengers", available at: http://www.lvcva.com/includes/content/images/media/docs/ES-YTD-2016.pdf (accessed 31 July 2020).

Las Vegas Convention and Visitors Authority (2020b), "LVCVA executive summary of Las Vegas, Laughlin, \& mesquite, NV tourism indicators", available at: https://assets.simpleviewcms.com/ simpleview/image/upload/v1/clients/lasvegas/ES_Jun_2020_aacebbf1-0d75-40d4-8e69ee7630432ad7.pdf (accessed 20 August 2020).

Lovelock, B. (2004), "New Zealand Travel agent practice in the provision of advice for travel to risky destinations", Journal of Travel and Tourism Marketing, Vol. 15 No. 4, pp. pp259-280, doi: 10. 1300/J073v15n04_03.

Martilla, J.A. and James, J.C. (1997), "Importance-performance analysis", Journal of Marketing, Vol. 41 No. 1, pp. 77-79, doi: 10.1177/002224297704100112.

Min, J.H., Lee, H. and Blum, S.C. (2019), "Spillover impact of non-gaming amenities on gaming volumes", Cornell Hospitality Quarterly, Vol. 60 No. 3, pp. 262-269, available at: http://dxdoi.org/ $10.1177 / 1938965518787453$.

Nevada Gaming Control Board (2020), "June 2020 Nevada gaming revenue and collections", available at: https://gaming.nv.gov/modules/showdocument.aspx?documentid=16982 (accessed 31 July 2020).

Occupational Health and Safety Administration (2020), "Guidance on preparing workplaces for COVID-19”, available at: osha.gov/Publications/OSHA3990.pdf (accessed 31 July 2020). 
Okada, S.S. (2020), "The reopening of Las Vegas casinos during the COVID-10 pandemic", Hospitality Net, 7 July, available at: https://www.hospitalitynet.org/opinion/4099529.html.

O'Neill, M.A. and Palmer, A. (2004), "Importance-performance analysis: a useful tool for directing continuous quality improvement in higher education", Quality Assurance in Education, Vol. 12 No. 1, pp. 39-52, doi: 10.1108/09684880410517423.

Perl, Y. and Israeli, A.A. (2011), "Crisis management in the travel agency sector: a case study", Journal of Vacation Marketing, Vol. 17 No. 2, pp. 115-125, doi: 10.1177/1356766710392478.

Pforr, C. and Hosie, P.J. (2008), "Crisis management in tourism”, Journal of Travel \& Tourism Marketing, Vol. 23 Nos 2-4, pp. 249-264, doi: 10.1300/J073v23n02_19.

Science Daily (2020), "People gambling less during the economic crisis", 8 July, available at: www. sciencedaily.com/releases/2013/07/130708103206.htm (accessed 31 July 2020).

Seymour, M. and Moore, S. (2000), Effective Crisis Management: Worldwide Principles and Practice, Cassell, London.

Shivdas, S. (2020), "Shut casinos hit Caesars as COVID-19 puts gambling industry in survival mode", Reuters, 11 May, available at: https:/www.reuters.com/article/us-caesars-results/shut-casinoshit-caesars-as-covid-19-puts-gambling-industry-in-survival-mode-idUSKBN22N2SJ (accessed 19 August 2020).

Shriber, T. (2020), "Macau resists closing Casinos second time, will press Beijing to lift IVS freeze", Casino.org, 3 April, available at: https://www.casino.org/news/macau-wont-close-casinos-asecond-time-but-it-wants-ivs-ban-dropped/ (accessed 31 July 2020).

Slatter, S. (1984), Corporate Recovery: A Guide to Turnaround Management, Penguin Books, London.

Smith, D. (1990), "Beyond contingency planning: towards a model of crisis management", Industrial Crisis Quarterly, Vol. 4 No. 4, pp. 263-275.

Smith, D. (2005), "Business (not) as usual: crisis management, service recovery and the vulnerability of organisations", Journal of Services Marketing, Vol. 19 No. 5, pp. 309-320, doi: 10.1108/ 08876040510609925.

Smith, D. and Sipika, C. (1993), "Back from the brink — post crisis management", Long Range Planning, Vol. 21 No. 1, pp. 28-38, doi: 10.1016/0024-6301(93)90230-D.

Snyder, G. and Harris, J. (2020), "California officials halt indoor dining as coronavirus surges", Los Angeles Times, 1 July, available at: https://www.latimes.com/food/story/2020-07-01/coronaviruscalifornia-restaurants-dining-rooms-closed-reopening (accessed 31 July 2020).

Spearman, C. (1904), "The proof and measurement of association between two things", The American Journal of Psychology, Vol. 15 No. 1, pp. 71-101, doi: 10.2307/1412159.

Stradbrooke, S. (2020), "Bars with slots get federal bailout, small casinos, not so much", Ayre Group, 15 April, available at: https://calvinayre.com/2020/04/15/casino/us-pandemic-bailout-smallcasinos-ineligible/ (accessed 31 July 2020).

Tabachnick, B.G. and Fidell, L.S. (2013), Using Multivariate Statistics, 6th ed., Pearson Education, Boston, MA.

The Washington Post (2020), "Where states reopened and cases spiked after the U.S. shutdown", available at: https://www.washingtonpost.com/graphics/2020/national/states-reopeningcoronavirus-map/ (accessed 31 July 2020).

Travel Weekly Asia (2019), "Report: Macau is the world city most reliant on tourism", available at: https://www.travelweekly-asia.com/Travel-News/Government/Report-Macau-is-the-world-citymost-reliant-on-tourism (accessed 31 December 2020).

Tse, A.C.B., So, S. and Sin, L. (2006), "Crisis management and recovery: how restaurants in Hong Kong responded to SARS", International Journal of Hospitality Management, Vol. 25 No. 1, pp. 3-11, doi: $10.1016 / j . i j h m .2004 .12 .001$.

Varma, T.M. (2020), "Responsible leadership and reputation management during a crisis: the cases of delta and united airlines", Journal of Business Ethics. doi: 10.1007/s10551-020-04554-w. 
Vaske, J.J. (2008), Survey Research and Analysis: Applications in Parks, Recreation and Human Dimensions, Venture Pub, State College, PA.

Woodyard, C. (2020), Can they be saved? Travel industry winners and losers of federal bailout, USA Today, 14 April, available at: https://www.usatoday.com/story/travel/2020/04/14/coronavirusstimulus-how-airlines-hotels-cruise-lines-fared-winners-losers/2987617001/ (accessed 31 July 2020).

World Travel and Tourism Council (2020), "Containing the spread of panic is as important as stopping the coronavirus itself, says WTTC", available at: https://wttc.org/News-Article/ Containing-the-spread-of-panic-is-as-important-as-stopping-the-coronavirus-itself-says-WTTC (accessed 31 July 2020).

\section{Corresponding author}

Kasra Ghaharian can be contacted at: kasra.ghaharian@unlv.edu

For instructions on how to order reprints of this article, please visit our website: 